This item was submitted to Loughborough's Research Repository by the author.

Items in Figshare are protected by copyright, with all rights reserved, unless otherwise indicated.

\title{
Gymnastics and child abuse: an analysis of former international Portuguese female artistic gymnasts
}

PLEASE CITE THE PUBLISHED VERSION

http://dx.doi.org/10.1080/13573322.2012.679730

\section{PUBLISHER}

(C) Routledge, Taylor \& Francis Group

VERSION

AM (Accepted Manuscript)

\section{PUBLISHER STATEMENT}

This work is made available according to the conditions of the Creative Commons Attribution-NonCommercialNoDerivatives 4.0 International (CC BY-NC-ND 4.0) licence. Full details of this licence are available at: https://creativecommons.org/licenses/by-nc-nd/4.0/

\section{LICENCE}

CC BY-NC-ND 4.0

\section{REPOSITORY RECORD}

Pinheiro, M.C., Nuno Pimenta, R. Resende, and Dominic Malcolm. 2019. "Gymnastics and Child Abuse: An Analysis of Former International Portuguese Female Artistic Gymnasts”. figshare. https://hdl.handle.net/2134/18865. 


\title{
Gymnastics and child abuse: an analysis of former international Portuguese female artistic gymnasts
}

\begin{abstract}
The growing competitiveness of modern sport means that children, from very early ages, are increasingly submitted to intensive training programmes. These programmes are problematic for young athletes not only because their developing bodies are particularly susceptible to different kinds of injuries, but because athletes are also particularly vulnerable to experiences of different kinds of abuses. Using data collected through semi-structured interviews this study examines the various kinds of abuse that former Portuguese female gymnasts underwent during their sporting careers. Interviewees were asked to reflect on their past experiences and discuss aspects of the gymnastics subculture. Weight control, training/competing with injuries and corporal punishment emerged as key themes. The study therefore shows that the physical and psychological abuse of young athletes occurs even beyond the confines of elite professional sport, and thus that a broader spectrum of athletes learn to consider these forms of exploitation and abuse as normal.
\end{abstract}

Keywords: Gymnastics; Abuses; Young athletes; Elite non-professional athletes; Power 


\section{Introduction}

The increasingly competitive character of modern sport means that in activities such as gymnastics children are submitted to intensive training programmes from very early ages (usually between the ages of 5 and 6) (Amaral, Santos and Ferreirinha, 2009). Children are encouraged by coaches and parents to practisce 4 to 6 hours a day (sometimes even up to 8 hours a day), 6 days a week (Amaral, Santos and Ferreirinha, 2009; David, 2005). Besides being long and repetitive, training is also physically and psychologically demanding (Gervis and Dunn, 2004). This raises specific physical and mental health concerns. According to Waddington (2000) such intensive programmes are problematic for young athletes, as their young, developing bodies are particularly susceptible to particular kinds of injuries (e.g. dislocations and fractures). Consequently it might be considered that children who train for high level sport may experience child abuse, which can be defined as: "all types of physical and/or emotional ill-treatment, sexual abuse, neglect, negligence and commercial or other exploitation, which results in actual or potential harm to the child's health, survival, development or dignity in the context of a relationship of responsibility, trust or power" (WHO, 2010).

Research indicates that athletes from various sports are-experience physical, sexual and emotional abuse (Brackenridge 2001; Brackenridge and Kirby, 1997; Donnelly, 1997; Ryan, 2000; Stirling and Kerr, 2007; Stirling and Kerr, 2009; Tomlinson and Yorganci, 1997; Young, 2004; Fasting and Brackenridge, 2009; Loland, Skirstad and Waddington, 2006;-Young, 2004). Evidence suggests that athletes in general, and gymnasts in particular, are especially 
vulnerable to a variety of forms of exploitation or abuse that can range from extreme diets and weight control, to verbal and emotional abuse, overtraining, corporal punishment, over-use injuries and training and competing while in pain or injured (David, 2005; Gervis and Dunn, 2004; Johns and Johns, 2000; Fasting and Brackenridge, 2009; Waddington, 2000). According to this literature, intensive training, competitive pressures and abuses in gymnastics often result in quite serious physical and psychological problems. For instance, many athletes develop eating disorders (Papathomas and Lavallee, 2010). Others have very low self-esteem. Physical and/or psychological injuries may last through an athlete's entire life.

Further, many young athletes involved in this kind of intensive training feel they have lost their childhood, and that they have grown up too soon. Brackenridge and Kirby (1997, p. 411) argue that these athletes describe their existence "as a feeling of the rest of their lives being on hold". Their lives revolve around school gymnasia-gymnasiums and sports arenas. They do not have time for outings, social life, parties, cinema, boy or girlfriends. That is, they do not have the time to do the things that are considered 'normal' for their non-sporting peers (David, 2005). This sense of 'lost childhood' is, according to David (2005, p. 60), "a powerful indicator of sport-related abusive trends".

This article seeks to explore the physical and psychological abuses experienced by female artistic gymnasts. Unlike existing studies which focus on the experiences of top international athletes that have achieved World Championship and Olympic Games success (Ryan, 2000, David, 2005), this study examines athletes in a country, Portugal, where international competitive success has been relatively limited. No Portuguese female gymnast has ever 
won a medal in a World or Olympic competition and Portuguese women's artistic gymnastics has only been represented in 8 Olympiads, the last being in 1996. PortugesePortuguese female gymnasts may be elite in the national context, but they would not be considered so internationally. While their time commitment to the sport may be extensive, their financial rewards are minimal. If, as the existing literature appears to suggest, abusive practices develop in relation to the increasing competitiveness of modern sport, then we might hypothesise that the relatively amateur, non-elite character of gymnastics in Portugal, would protect these athletes from the more extreme elements of abuse. However, as this article illustrates, there is evidence to suggest that female Portuguese gymnasts experience similar kinds of abuse to that charted among world class professional athletes.

\section{Theoretical considerations}

Given the manifest and serious nature of the abuses inflicted on young athletes, it is important to explain athletes' widespread 'tolerance' of such experiences. This can be done by conceiving of child athletes as part of 'sportsnets' (Nixon, 1992), or 'figurations' (Elias, 1980). The term 'sportsnet' was introduced by Nixon (1992) to define the webs of interactions and relations of power which, link members of the sport social network. On the other hand, Elias (1980) used the term figuration to describe interdependency ties of mutually orientated and dependent people. For Elias, relations may be direct or indirect and while they cannot be precisely measured, they can be felt by individuals belonging to 
different figurations. Humans are always and everywhere part of these figurations, which increase in size and complexity as societies develop.

Roderick (1998), working within an Eliasian perspective, argued that while there are important similarities between these concepts, there are also a number of key differences and thus ways in which Nixon's work might be improved. Nixon's perspective is athlete-centric, concentrating on direct relationships such as athlete-athlete, athlete-coach. While Nixon (1992) acknowledges that athletes are aware of the influence of 'significant others' on the way in which they experience the social world, Elias's notion of the figuration alerts us to the various direct and indirect actors, such as medical staff, supporters, media, parents, school, other peers, etc. that should also be studied to fully understand the sportsnet or figuration. As Roderick notes (1998, p. 70), "Elias emphasised Formatted: English (U.K.) that people do not have to be aware of, or interact with, others to be within the same relational network and influenced by [them] $\ldots$ and he argued that a perspective which is confined to direct relationships tends to limit one's understanding of social processes". While we are not always completely aware of the influence of others on our behaviour/beliefs, it is also true that we are not always completely aware of our influence on others' behaviours/beliefs. Formatted: English (U.K.)

Formatted: English (U.K.) Furthermore, Roderick is critical of Nixon's conclusion that sportsnets are 'conspiratorial', arguing instead that it is more adequate to conceptualise athletes as one interdependent part, rather than the subject, of a broader network. Consequently we prefer the term figuration to sportsnet as it enables us to more adequately describe the social relations, and therefore the child abuse within, the sport context. The work of Elias (1980) will be of keen importance throughout this paper. 
Following Elias, as gymnasts become more enmeshed in this set of relations they will be likely to be more influenced by their interdependence with other members of the figuration. According to Maguire (2002), a 'sports ethic' ${ }^{1}$ is learnt early on and becomes normalised and taken for granted by the gymnasts. Maguire (2002, p. 3) argues that some key features of the 'sports ethic' are "a willingness to make sacrifices [...] and a tacit acceptance that there is no limit to the pursuit of the ultimate performance". Through socialisation into their sport, athletes come to incorporate prominent beliefs held by other members within the gymnastics figuration. The aspiration for competitive success masks the distress of different forms of abuse and makes it difficult for young athletes to challenge or resist the behaviour of their coaches. This may explain why athletes do not question behaviours which are often presented as 'the only way' to achieve sporting goals. In other words, these gymnasts have a strong emotional involvement that may distort their understandings of both social processes and (un)ethical practice. This makes it difficult for them to stand back and examine their personal experiences in a more detached manner (the relationship between involvement and detachment and the generation of knowledge is discussed further in the methodology section). Young gymnasts come to incorporate the norms, values, beliefs, dispositions and behaviour patterns of the broader gymnastics group, and thus their habitus develops in a specific way. ${ }^{2}$ Moreover, whenever the pressure or tensions to which their groups are exposed increase, their level of involvement gets higher and it becomes more difficult for them to approach such situations in a more detached way. Elias (1980) called this a double-bind situation; a vicious circle in which the attributes required to resolve a problem are repressed by the very contextual 
conditions which create the problem. It is in this context that forms of 'abuse' (ranging from training while injured to physical and sexual assault) tend to go unchallenged (see Malcolm 2011 for an Eliasian discussion of athletes, knowledge and habitus).

The key interdependencies in which young athletes are enmeshed in the gymnastics figuration, and thus those which are central to an understanding of the abuses they experience, relate to coaches, parents, sports club administrators and the national sport federation. When analyzinganalysing coaches' influence over athletes, it is important to take into account coaches' relative age, sex, knowledge, access to resources (i.e. their own network of relations), and their esteem based on past sporting success. As stated by Gervis and Dunn (2004), a coach builds their reputation according to athletes' results, which means they have a great deal to lose if their athletes are not successful. Through their gymnasts' results, coaches strive for recognition, success and seek to increase their influence within their sport. Their careers and income depend greatly on their athletes' performances (Stirling and Kerr, 2009). Apart from their own personal expectations, coaches are also subject to external pressures from sports club administrators, national federation officials and parents who also expect good results from them. These expectations and pressures may lead to decisions that go against the well-being of the athlete (Donnelly, 1997) and thus lead to, or foster, abuse.

On the other hand, it is important to note that athletes also require coaches' specialised knowledge and skills in order to achieve success, resulting in an athlete's dependency on his/her coach (Palframan, 1994 cited in Stirling and Kerr, 2009). This mutual dependency leads to a very close relationship which 
shapes the habitus of athletes in accordance to the norms of the sport. Athletes that reflect the prominent culture of the gymnastics figuration, that have a 'good attitude', are employed as "role models for imitation" (Loland, 2011, p. 18). In the same way, those who are not prepared to make sufficient sacrifices in order to achieve success "are likely to be stigmatized as not having the 'right attitude"' (Roderick, Waddington and Parker, 2000, p. 169). This process helps to legitimate coaches' authority, and thus the coaches' ability to control the behaviour or the athlete (Stirling and Kerr, 2009). It is noteworthy that "young athletes may lack the psychological maturity necessary to think critically about these relationships" (Stirling and Kerr, 2009, p. 235); in other words, to be relatively detached from their situation.

Besides coaches, parents also play an important role in the gymnastics figuration. Although thinking that they have the best interests of their children at heart, many tend to place great trust in the coach, sports administrators and medical staff (Donnelly, 1997). This may be due to a lack of knowledge about the sport in which their child is involved, a lack of knowledge of the training techniques, or an inability to understand the complex set of interdependencies involved in elite sport. Like their children, parents are immersed in this specific culture and come to embody cultural practices and ideas. As they become increasingly established actors in the figuration, parents start to impose expected behaviours and attitudes on athletes through acts of regulation and power (McMahon and DinanThompson, 2011). Parents often want to see some return for their personal and financial investment so they exercise different kinds of pressure upon coaches and their own children. This aligns with the needs and expectations of national federation officials and clubs administrators who 
justify their annual investments through competitive results. Pace Roderick (1998), this network of interdependencies shows that various actors coalesce to exert similar kinds of pressure on the gymnast, rather than necessarily conspiring as Nixon suggests. Even if some members of the figuration may appear to be relatively powerful, all influence the gymnast's performance and commitment, and therefore contour social action - which includes abuse - in particular ways.

The gymnast, although being in a relatively weak position, is not powerless in the sense that their actions cannot influence the actions of others. Ironically the various actors discussed are highly dependent on the gymnast for the realisation of their own goals. However, in this specific situation and due to their relative youth, they commonly develop a habitus which includes a relative disinclination to question the authority of adults, and thus which makes them particularly vulnerable to exploitation and abuse (Waddington, 2000). The social position of these young athletes "makes it difficult for them to resist adult power" (Parton, 1985, cited in Cense and Brackenridge, 2001, p. 68). In a sport such as gymnastics, "where they have less skill or knowledge than their coaches and instructors" (Cense and Brackenridge, 2001, p. 68), their low status and relative dependence is continually reinforced.

\section{Methodology}

In 2006 the first and second named authors conducted six interviews with former female gymnasts (at the time of interview between 25 and 33 years of age). Each interviewee had started practising gymnastics daily for 3 to 4 hours 
from a young age (5 or 6 years old). Working through an initial interviewee/gatekeeper, convenience sampling and snowballing techniques were used to develop the sample. All the interviewees represented Portugal in major international competitions such as European and World Championships and Olympic Games. All were retired from gymnastics at the time of this study. Four were still involved in gymnastics as coaches. All have a bachelor degree in physical education or sport.

Subsequent participants were firstly contacted by telephone in order to assess their availability to take part in the research and arrange a suitable time and place for the interviews. Interviews lasted between 30 to 75 minutes and occurred in quiet public places near the interviewee's residence. The confidentiality and the provision of a risk assessment were of keen importance during the interviewing process. A guarantee was given to the gymnasts that they will not be identified at any time, so any traces leading to their identification were removed, such as names and clubs.

Due to the confidential and sensitive nature of the data, face-to-face interviews were conducted to help establish trust and rapport. Interviews were semistructured and consisted of relatively open questions focussed upon interviewees, structured around interviewees' experiences of pain and injury in sport, their perceptions of pressure placed upon them by their coaches and parents, and their perceptions of abuse, weight control and eating disorders. The guiding questions served to orientate the interview, so that interviewer and interviewee did not deviate from the objectives set for this work, thus ensuring that information on consistent themes was obtained. However, while using a set of pre-defined questions, during the interview it was possible to change the 
order of questions, to adapt questions in order to meet the personal experiences of the interviewees and to insert other questions in order to obtain more information in relation to emerging issues. Moreover, we wished to enable participants to talk about their own experiences in their own words (Quivy and Campenhoudt, 1998), and elaborate on areas they deemed to be of particular interest or importance. Thus, the interviewees were encouraged to reflect on their past experiences and discuss relevant aspects of the gymnastics subculture. The main strategy used to help the athletes to revive their experiences was an 'emotional recall', as_advocated by Ellis and Bochner (2000). By emotionally reviving their past experiences athletes may be able to remember such experiences in greater detail.

All interviews were recorded and transcribed verbatim. Data was coded with the help of the software Nvivo 8. Coding is, according to Neuman (2003), the organisation of the raw data into conceptual categories to create themes or concepts to aid data analysis. The interviews were subjected to thematic analysis in an attempt to find common elements across research participants and the events they reported. However, the goal was to develop the best classification system in which the data fits with minimal overlap between categories (Côté, Salmela, Baria and Russell, 1993). The data units (statements, sentences and so on) were clustered into common themes so that similar units were grouped together and separated away from units with different meanings. Through this analysis, data was divided into three main themes: weight control; training and competing while in pain or injured; corporal punishment. Finally data extracts were translated into English by the authors and, as closely as possible, appear as they were told. 
During the analysis of the literature and the interviews, we were always concerned with the degree to which our level of involvement could influence the interpretation of data (Elias, 1987). It is important to note that we were studying something with which one of the researchers was more-or-less involved (the lead author is a former international gymnast). Nevertheless, through her distanciation from the gymnastics figuration (i.e. in developing an alternative, academic, career) this researcher is now able to combine 'insider' knowledge of this figuration with a relatively detached perspective. We consider that this aspect is important and necessary if we wish to develop more adequate knowledge and greater awareness of this issue. Our perceptions and 'insider knowledge' of this sport would inevitably influence the questions raised during the data collection, and the analytic prioritisation of themes such as physical and emotional abuse. That said, when collecting data through interviews, and during the data analysis phase, we always tried to put aside personal ideas and beliefs. In accordance with our Eliasian framework we attempted to analyse the relevant aspects in as detached a manner as possible through, for example, controlling emotional involvement and being reflexive about our role in the production of knowledge (Kilminster, 2004). One of the common criticisms of qualitative research relates to the fact that it is difficult to be completely certain that the interpretations are valid or reliable. However, with one of the research team being a former international gymnast, with experience of the "very limiting, often painful downside" of gymnastics (Messner and Sabo, 1990 cited in Young, McTeer and White, 1994) we believe that our decoding of the data is relatively accurate. While we cannot claim that this data is representative of gymnasts in 
Portugal more broadly, its logical consistency and empirical similarity to other studies suggests a relatively high degree of reliability.

\section{Results and discussion}

\section{I - Abuses while training and competing}

\section{Weight control}

It is widely accepted that female gymnasts benefit from being relatively small and lean (Ryan, 2000). The artistic ability and femininity observed in past decades have more recently been superseded by complex jumps and moves that can be more easily performed by girls with more infantile bodies (Benn and Benn, 2004; David, 2005). Therefore, great pressure is placed upon gymnasts' weight. Moreover, along with technical skills, judges and spectators place great importance on appearance, gracefulness and elegance. This may compel coaches to constantly control athletes' weight during training sessions. This can be seen, in a Foucauldian perspective, as a surveillance arrangement that "functions anonymously to engage athletes in a disciplinary practice to maintain an ideal weight" (Johns and Johns, 2000, p. 227). Interviewees provided the following statements in this regard:

I don't know if we were weighed every day, but there was a pressure upon our weight. The coach made it quite clear that if we didn't lose weight, we would experience great difficulties when doing the exercises.

In artistic gymnastics all the athletes know that the heavier they are the more difficult it is to practise. I never in my life dared to eat a big cookie in 
front of the coach, for respect, because he/she had taught us that to maintain our weight we had to be careful with what we ate.

Coaches usually attempt to control athletes' weight by telling them and their parents about the importance of having the 'right weight'. Indeed, "they are relentless about weight because physically round gymnasts don't win" (Ryan, 2000 , p. 11). Weight control is even more intense when major competitions are near.

My coaches weighed me weekly, other times daily. Most of the time we did not want to be weighed. If we could run away from the scales we would just do it, just because yesterday I ate a cake, or because I had had a birthday party over the weekend, Christmas, Easter.

Coaches put pressure on athletes' weight and encourage them to do whatever they can to looselose it, including taking off their clothes.

We were controlled and weighed every day and when we knew we were going to be weighed, we went to the bathroom trying to do everything we could. We took off the biggest number of clothes possible, in order to avoid a single extra gram. If the weight was greater than normal, he/she was annoyed by us. If by any chance our weight increased $1 / 2 \mathrm{~kg}$ he/she would say "tomorrow this $1 / 2 \mathrm{~kg}$ has to be gone" and we stood there thinking on what we had to do.

Sometimes coaches verbally and emotionally abuse their athletes by calling them names, humiliating them, yelling and so on, in order to stimulate and to push them to the limit (David, 2005). This is more frequent whenever athletes fail to meet weight targets. Coaches impose a certain weight on their athletes 
and if they exceed such weight the coach threatens them with withdrawal of either competition or food. In the words of one interviewee:

Sometimes when we did not lose weight the coach decided that we were not allowed to have dinner, and we ate only the next day at breakfast.

Furthermore, 'imposed' food abstinence is also used as a mean of punishment for a poor practice. Another gymnast recalled,

The first time I went abroad, I went with a coach who was not mine. In this period of training we had physical preparation at $7.30 \mathrm{am}$, then we had breakfast at $10.00 \mathrm{am}$. If the morning practisce did not run well, the punishment was not to have lunch. During the afternoon, if the practise did not run well, once again, I did not have dinner.

According to Ryan (2000), eating disorders amongst female gymnasts are common and more frequent than amongst female athletes from other sports. Such eating disorders are not only related to weight control, they are also associated with a lack of self-esteem and poor self-image:

We felt shame whenever we were fatter. When taking part in a competition dressed with a gymnastics leotard, the judges frequently comment that this or that gymnast is fatter. We knew that they commented on.

When I was fatter the coach was able to make me feel really bad by saying that I was fat, with an enormous butt and with big thighs. The coach managed to develop in me a body complex. 


\section{Training and competing while in pain or injured}

The exploitation and abuse of children in gymnastics can also be seen through the pressure placed upon gymnasts to continue training and competing while in pain or injured. By doing this, the athletes face the risk of developing longer term injuries and permanent damage to their health. Several studies indicate that it is rare to find an elite athlete who has trained or competed throughout his/her entire career without a single injury (Charlesworth and Young, 2006; Waddington, 2006; Young, McTeer and White, 1994). In our research, all the gymnasts interviewed mentioned that they had, at least once, competed while in pain or injured.

According to some authors (Charlesworth and Young, 2004, 2006; Liston, Reacher, Smith and Waddington, 2006; Roderick, Waddington and Parker, 1999) athletes believe that pain and injury are an intrinsic and natural part of the sporting activity. This 'good attitude', or the normalization of risk, pain and injury, was evident among the interviewees.

I remember having a micro-rupture before a period of training in [a city] and although being advised by the doctor to stop for 2 weeks. After one week I was already training. Although in pain, I did not complain because my main concern was to participate in that period of training, for this I had to lie to my coach saying that I was well.

Sometimes I told the coach but (s)he didn't care that much, because if we stopped practising we would decrease our performance and could not attain what they wanted. I practised many times with pain. I got used to pain. It is a normal thing in gymnastics. 
Ryan (2000) notes that athletes, and gymnasts in particular, learn to manage pain and injuries from very early ages if they want to succeed in the sport. From the moment they start training, athletes learn through observation that injury is a frequent occurrence. As the former Romanian gymnast Andrea Raducan (Olympic champion) has stated: "from the moment I went to the gymnastics hall for the first time, I knew that without the will, without getting injured and without being courageous, you cannot reach the top" (cited in David, 2005, p. 68). But a gymnast also races against time in order to become a perfect machine before her body matures too much. It is a race against puberty. In this context, time off due to a severe injury and with a long recovery period entails the risk of dropping out of the sport. Thus, the consequences of some time off due to injury can have a major influence on the athlete's sporting career. This can be observed in the description of one of our interviewees:

Before the [competition] I had my first serious injury, and it was an important time of my sporting career. In the competition warm up, I twisted my ankle, and that was a very important international competition. When I got injured I felt completely frustrated. I had been practising all my entire life for that competition and I got injured one month before. At the time I tried to compete but it was impossible. I had a sprained ankle with a joint injury. This means that it would have been better to break my foot. I was still able to recover in a month but it was impossible to attend to the competition. In gymnastics you lose everything really fast and I lost a lot of strength.

Many athletes admit taking painkillers in order to be able to practise and compete while in pain or injured: 
I remember having a serious sprained ankle and I did two infiltrations (injections of painkillers) only to be able to compete. At the time, I didn't know that it was harmful to my health.

I never stopped training. Once, I had a rupture in my thighs and I kept training because it was before a major competition. It was a national competition that was going to determine the athletes that would represent Portugal in an international event. I knew that if I stopped I would lose that opportunity. I practised in spite of being advised by the doctor to stop. At the time I took some painkiller injections to ease pain and on the competition day I participated with bandages. However, I was not able to do some exercises because of the pain. I didn't compete normally, I felt limited due to the injury.

With the help of painkillers, athletes are able to continue practising and competing while in pain or injured. This increases the risk of acquiring overuse and recurrent injuries that through time can become permanent. People who are unaware of the demands of sporting performance will find it difficult to comprehend the value system of the athlete.

I have a permanent injury in my back that affects me in my everyday life. If I stand up for a long time, my back hurts. I have these pains for so long that I got used to them. I have one scoliosis and a fracture in the L-5 (vertebra). It is an injury of fatigue and overtraining.

I have a problem resulting from gymnastics. Due to overtraining and the constant impacts, I have a loose bone in my heel. When I am doing something like rotating my foot, the tendon passes behind that loose 
bone becoming stuck. This impedes me to move my foot and I cannot do anything else. This is a result of gymnastics. Even after finishing gymnastics, I walked one week with crutches, and another one without.

The intensive training, the great pressure placed upon athletes concerning their weight, and the encouragement to continue training and competing while in pain or injured can be regarded, according to David (2005), as forms of physical abuse.

\section{Corporal punishment}

Corporal punishment is an additional physical abuse to which athletes are frequently submitted. Through our interviewees it was possible to observe that this situation happened in Portuguese gymnastics:

Normally, the coach asked me 3 times why I haven't done the exercise. At the third he/she slapped me in the face. With a very serious face he/she asked me:

"Why haven't you done it?" (Once)

"Why haven't you done it?" (Twice)

"Why haven't you done it?" (Third). At this time and he/she slapped me in the face. He/she would do that until $\underline{\text { until I }}$ answered. Although knowing that by the third time I was going to get a big slap, I was not able to open my mouth. This happened because of the pressure. That happened frequently. He/she acted that way when I was scared and took too long to do an exercise, not because I failed it.

One time, due to some errors in the execution of an exercise in vault, I finished the jump and the coach kicked and slapped me in the legs from 
the springboard until the place where I started running. Whenever I started a new jump, after cleaning up my tears, there was him/her again and I was beaten once more. I was beaten until the beginning of the track and in five seconds I had to be ready to do another jump.

Another interviewee recalled that once, when doing some exercise on the beam, the coach reacted quite violently:

I remember that I was not able to do some exercise and he/she called me and pushed me to the stairs and said: "if you do not want to do it, leave". I remember that when I was walking towards him/her from the beam to the place where he/she was I was thinking about what was going to happen. I think that was then that he/she pushed me down the stairs and I fell.

Because actors in these figurations are so closely bonded, such behaviour normally goes unquestioned. It is often seen and considered as part of sport and it tends to occur behind closed doors (Gervis and Dunn, 2004). In this regard, Ryan (2000) mentions that inside the gymnastics hall, participants develop what can be called a code of silence. That is to say, no one questionsquestions or talkss about what happens inside this sport.

I didn't talk that much with my parents about my problems in the gym. I didn't feel the need to talk to them especially because I felt that they could not help me... They were going to help me on what? They weren't inside the gym, they didn't hear.

I never told my parents anything and the fact of not telling them, it was a matter of being afraid of being taken out from gymnastics. 
I never told a single thing to my parents, because I was afraid that they would forbid me to continue practising.

Although these gymnasts were clearly aware of the deviant nature of the acts they experienced, their commitment to the sport ethic, and their sense of dependence on the perpetrators, led them to develop a heightened level of tolerance towards these abuses. Keeping these events private might be seen as something desirable within this figuration and might also mean staying actively involved in the sport, being chosen for the national team or even being able to win competitions.

\section{II - Parental involvement}

Besides coaches, parents also play an important role in fostering particular subcultural norms and thus tolerating abuse. For many parents, their children's involvement in sport represents a great investment in terms of energy, time and money. Therefore, they "openly or tacitly, acquiesce in the imposition of excessive harsh training regimes on their children in the hope of making them into champions" (Waddington, 2000, p. 50). As two interviewees stated:

My mother did a lot for my coach. If he/she told my mom that she could only give me an orange, she would give me just an orange. I don't judge my mom for what she did but I think that my coach made my mom's mind.

My parents were usually against me and on the coach side, everything that happened was my fault, I never talked that much with my parents 
about things related with training or gymnastics. ... the coach was always right. (...) The coach, for them, was a 'real God'.

This data supports the literature which shows that parents tend to place considerable trust in the coach (Donnelly, 1997; McMahon and DinanThompson, 2011). The existence of a code of silence, as previously mentioned, may be related to a lack of parental knowledge about the sport and about what happens during training sessions. But for many mothers and fathers, being a parent of a high performance athlete "becomes a significant part of their identity" (Donnelly, 1997, p. 399). The way they act may place additional pressure upon their child, who "recognizes that his/her desire to change goals, or to retire, poses a threat to the identity of at least one of his/her parents" (Donnelly, 1997, p. 399).

My parents did everything for my sporting career. I remember my father leaving his job to take me to the gym, to pick me up at the end of the training at $1 \mathrm{pm}$. They did everything that was needed, they never put anything in front of my career. If the coach decided that I could only have holidays in August, my parents would have holidays only in August.

Athletes may not wish to disappoint parents who have made a great investment in their child's sport career. Consequently child athletes may feel compelled to continue practising while in pain and injured and tolerate different kinds of abuse. 


\section{Conclusion}

All the examples of physical and psychological abuse reported above stem from the actions of coaches whose future and reputation depended greatly on the performance of their athletes. Due to all that is at stake, many "do not hesitate to abuse young athletes verbally and emotionally, using insults and humiliation to provoke their charges' anger, which they consider a powerful stimulant and a prerequisite to character building, and pushing them to the limit and beyond" (David, 2005, p. 84). While many coaches may believe they are working in the best interests of the athletes, they usually tend to place a great emphasis on the athletes' body and its performance, instead of focusing on the athlete as a human being (Donnelly, 1997).

It is within the figuration that athletes learn the distinctive gymnastics habitus. Athletes learn to consider these forms of exploitation and abuse as something normal in sport. Since the moment they start practising, athletes are enmeshed in a sporting culture that tends to normalize risk, pain, injury and abuses. For the athletes, this is seen as being part of a "sport ethic". This research shows that adherence to the sport ethic is not something which only occurs in world class and highly profession sporting contexts, but may be more generally evident within gymnastics.

Gymnasts are members of a sport figuration that "shape (their) individual processes of growth and development, and the trajectory of individual lives" (Loyal and Quilley, 2004, p. 5).That figuration will constrain them to act in ways that "they would not act except under compulsion" (Elias, 1980, p. 102). The more deeply athletes are involved in a sports figuration "the more likely it seems 
that the culture of risk will provide the only terms or stories for them to deal with the risks of pain and injury" (Nixon, 1993, p. 190). As they become more enmeshed in the sports figuration, the athletes will likely be more influenced by other members of the figuration and therefore increasingly conformist within this culture. Therefore, "athletes' efforts to deal with pain, injuries, intensive training and weight control are likely to reflect prominent beliefs from the culture of risk held by coaches" (Nixon, 2004, p. 85), and other gymnastics figuration members. But we further contend that young athletes, with their personality undergoing relatively rapid development, are more vulnerable to such influences than are older athletes and that this could be one of the reasons why gymnastics appears to have a higher propensity to various kinds of physical and psychological abuse.

Children are usually in a relatively weak position (although not completely powerless) in relation to the people who run and/or coach in clubs (Waddington, 2000). This makes them particularly vulnerable to exploitation and abuse. Such vulnerability is partly explained by reference to the power relations between adult and child. From very early ages and in various contexts, children learn that they are expected to do what adults tell them to do. So, for many children, it is difficult not to follow adults' instructions. Their phase of life-course is such that they are frequently acquiring new forms of knowledge and are socially rewarded for their developing habitus. This applies to the sports figuration in the adult/coach-child relationship. Children follow coaches' instructions because they are adults and as children they are expected to follow adults' instructions. This has implications for their education and even their developing personalities 
if, from young ages, they learn about the contradictions and inconsistencies of trusting adults.

This analysis clearly shows the existence of a power imbalance and whenever this occurs there is a potential for abuse to take place (Cense and Brackenridge, 2001). Moreover, these power inequalities are compounded in sport figurations. Athletes, although not powerless (since there is no one without some sort of power), are generally in a weaker position in relation to adults and in a relatively dependent position in relation to coaches who are more powerful. According to Waddington (2000), for many athletes, coaches are seen as the people who control the access to desired goals, such as selection for national teams. In a performance context coaches are in a privileged position since they claim to have the knowledge, experience, wisdom and resources that lead to athletic success (Johns and Johns, 2000). This power imbalance supports the existence of coaches' disciplinary practices in order to achieve victory (Heikkala, 1993). These practices These practices lead to a normalization, eliminating most of the social and psychological differences producing 'useful' and 'docile' bodies and subjects (Heikkala, 1993).

Our conclusion is not that children (and in this specific case young girls) should be withdrawn from gymnastics. Rather, we seek to raise people's consciousness that, in this sport, we are dealing with children who, because of their vulnerability, need to be protected from abusive behaviours and situations. This aspect is clearly stated in the 1989 United Nations Convention on the Rights of the Child that was signed by Portugal in 1990. Our concern is that parents and their teachers need to more fully understand what participation in elite gymnastics involves. In particular, athletes need to be informed of this. 
Donnelly's (1997, p. 402) argument, is compelling; "knowledge becomes the best weapon against the excesses of the high-performance sport system where children are concerned". By contributing to a more adequate understanding of the gymnastics world, people, and especially parents, will be enabled to take more informed decisions about their child's involvement in gymnastics.

Notes

1. The 'sports ethic' is defined by Coakley (2003, p. 168) as an "unwritten set of norms that many people, in power and performance sports, have accepted as the dominant criteria for defining what it means to be an athlete and to successfully claim an identity as an athlete".

2. While the concept of habitus is more closely associated with Bourdieu, it is a term also used by Elias. Habitus is used to evidence the importance of the influence of others upon individuals' behaviours, ways of talking, postures, etc-.:Due to the networks of social relations in which people are enmeshed, they incorporate the norms, values, beliefs, etc. which become manifest in their attitudes, emotions and embodied actions and thus appear as a kind of 'second nature' (Elias, 1989; Elias, 1990).

\section{References}

Amaral, L., Santos, P. \& Ferreirinha, J. (2009) Caracterização do perfil lesional em ginástica artística feminina: um estudo prospectivo das ginastas Portuguesas de competição ao longo de uma época desportiva, Revista Portuguesa de Ciências do Desporto, 9(1), 43-51. 
Benn, T. \& Benn, B. (2004); After Olga: developments in women's artistic gymnastics following the 1972 'Olga Korbut phenonemon”, in: E. Dunning, D. Malcolm \& I. Waddington (Eds.) Sport Histories: Figurational Studies of the Development of Modern Sport (Abingdon, Routledge), 172-190.

Brackenridge, C. (2001) Spoilsports: understanding and preventing sexual exploitation in sport (London Routledge).

Brackenridge, C. \& Kirby, S. (1997) Playing safe: assessing the risk of sexual abuse to elite child athletes, International Review for the Sociology of Sport, 32(4), 407-418.

Formatted: Font: Not Italic

Cense, M.; \& Brackenridge, C. (2001) Temporal and Developmental Risk Factors for Sexual Harassment and Abuse, European Physical Education Review, $7(1), 61-79$.

Charlesworth, H. \& Young, K. (2004) Why English female university athletes play with pain: motivations and rationalisations, in: K. Young (Ed.) Sporting bodies, damaged selves - sociological studies of sports-related injury (Amsterdam, Elsevier),163, 163-180.

Charlesworth, H. \& Young, K. (2006) Injured female athletes - experiential accounts from England and Canada, in: S. Loland, B. Skirstad \& I. Waddington (Eds.) Pain and injury in sport - social and ethical analysis (London and New York, Routledge), 89-106.

Coakley, J. (2003): Sport in society - issues and controversies (Boston, McGraw Hill Higher Education) 
Côté, J., Salmela, J., Baria, A. \& Russell, S. (1993) Organizing and interpreting - unstructured qualitative data, The Sport Psychologist, 7, 127-137.

David, P. (2005) Human rights in youth sport - a critical review of children's rights in competitive sports (London and New York, Routledge).

Donnelly, P. (1997) Child labour: applying child labour laws to sport, International Review for the Sociology of Sport, 32(4), 389-406.

Formatted: Font: Not Italic

Elias, N. (1980) Introdução à Sociologia (Lisboa, Edições 70).

Elias, N. (1987) Involvement and Detachment (Oxford, Blackwell).

Elias, N. (1989)- O Processo Civilizacional (1 ${ }^{\text {st }}$ ed. Vol. 1)- (Lisboa ${ }_{1} \div$ Publicações Dom Quixote).

Elias, N. (1990): O Processo Civilizacional (2 ${ }^{\text {nd }}$ ed. Vol. 2) $=\left(\right.$ Lisboa $_{1} \div$ Publicações Dom Quixote).

Ellis, C., \& Bochner, A. P. (2000) Autoethnography, personal narrative, reflexivity: $\underline{\text { Researcher as subject, in: N. K. Denzin \& Y. S. Lincoln (Eds.), The handbook of qualitative }}$ research (2 ${ }^{\text {nd }}$ Ed.) (London, Sage), 733-768.

Fasting, K. \& Brackenridge, C. (2009)= Coaches, sexual harassment and education, Sport, Education and Society, 14(1), 21-35.

Gervis, M. \& Dunn, N. (2004) The emotional abuse of elite child athletes by their coaches, Child Abuse Review, 13, 215-223.

Heikkala, J. (1993)- Discipline and excel: techniques of the self and body and the logic of competing. Sociology of Sport Journal, 10, 397-412.

Formatted: Font: Not Italic Formatted: Font: Not Italic, Superscript

Formatted: Font: Not Italic Formatted: Font: Not Italic Formatted: Font: Not Italic 
Johns, D. \& Johns, J. (2000)- Surveillance, subjectivism and technologies of power: an analysis of the discursive practices of high-performance sport, International Review for the Sociology of Sport, 35(2), 219-234.

Formatted: Font: Not Italic

Kilminster, R. (2004) From distance to detachment: Knowledge and selfknowledge in Elias's theory of involvement and detachment, in: S. Loyal \& S. Quilley (Eds.), The sociology of Norbert Elias, (Cambridge $e_{2} \div$ Cambridge University Press), 25-41.

Liston, K., Reacher, D., Smith, A. \& Waddington, I. (2006) Managing pain and injury in non-elite Rugby Union and Rugby League: a case study of players at a British University, Sport in Society, 9(3), 388-402.

Formatted: Font: Not Italic

Loland, S. (2011) The normative aims of coaching - The good coach as an enlightened generalist, in: A. Hardman and C. Jones (Eds.), The ethics of sports coaching (New York, Routledge), 15-22.

Loland, S., Skirstad, B. \& Waddington, I. (2006)- Pain and injury in sport - social and ethical analysis (London and New York, Routledge).

Loyal, S. \& Quilley, S. (2004) The Sociology of Norbert Elias (Cambridge, Cambridge University Press).

Maguire, J. (2002) Performance Efficiency or Human Development? Reconfiguring Sports Science. Paper presented at the Idrett, Samfunn og Frivillig Organisering Conference, Olso $\underline{\text { Oslo. }}$

Malcolm, D. (2011) Sport Medicine, Injured Athletes and Norbert Elias's Sociology of Knowledge, Sociology of Sport Journal, 28(3) 284-302. 
McMahon, J. \& DinanThompson, M. (2011) 'Body work - regulation of a swimmer body': an autoethnography from aan Australian elite swimmer, Sport, Education and Society, 16(1), 35-50.

Formatted: Font: Not Italic

Neuman, W. (2003) Social research methods: qualitative and quantitative approaches (Boston, Pearson Education).

Nixon, H. (1992) A Social Network Analysis of Influences on Athletes to Play With Pain and Injuries, Journal of Sport and Social Issues,- 16(2), 127-135. Nixon, H. (1993) Accepting the Risks of Pain and Injury in Sport: Mediated Cultural Influences on Playing Hurt, Sociology of Sport Journal, 10(2), 183-196.

Nixon, H. (2004) Cultural, structural and status dimensions of pain and injury experiences in sport, in: K. Young (Ed.), Sporting Bodies, Damaged Selves Sociological Studies of Sports-Related Injury (Amsterdam, Elsevier), 81-97.

Papathomas, A. \& Lavallee, D. (2010) Athlete experiences of disordered eating in sport, Qualitative Research in Sport and Exercise, 2(3), 354-71.

Quivy, R. \& Champenhoudt, L. (1998) Manual de investigação em ciências de investigação em ciências sociais (Lisboa, Gradiva).

Roderick, M. (1998) The sociology of risk, pain and injury: A comment on the work of Howard L. Nixon II, Sociology of Sport Journal, 15, 64-79.

Roderick, M., Waddington, I. \& Parker, G. (1999) Managing injuries in professional football: a study of the roles of the club doctor and physiotherapist (Leicester, Centre for Research into Sport and Society). 
Roderick, M., Waddington, I., \& Parker, G. (2000) Playing Hurt - Managing Injuries in English Professional Football, International Review for the Sociology of Sport, 35(2), 165-180.

Formatted: Font: Not Italic

Ryan, J. (2000) Little girls in pretty boxes - the making and breaking of elite gymnasts and figure skaters (New York, Warner Books).

Stirling, A. \& Kerr, G. (2007) Elite female swimmers' experiences of emotional abuse across time, Journal of Emotional Abuse, 7(4), 89-113.

Formatted: Font: Not Italic

Stirling, A. \& Kerr, G. (2009) Abused athletes' perceptions of the coach/athlete relationship, Sport in Society, 12(2), 227-239.

Formatted: Font: Not Italic

Tomlinson, A. \& Yorgancy, I. (1997) Male coach/female athlete relations: gender and power relations in competitive sport, Journal of Sport \& Social Issues, 21(2), 134-155.

Formatted: Font: Not Italic

United Nations. (1990) Declaração universal dos direitos da criança. Retrieved January 2011, from Associação Portuguesa de Famílias Numerosas: http://www.apfn.com.pt/declaracao_universal_dos_direitos_da_crianca.htm

Waddington, I. (2000) Sport, health and drugs: a critical sociological perspective (London and New York, E \& FN Spon).

Waddington, I. (2006) Ethical problems in the medical management of sports injuries: a case study of English professional football, in: S. Loland, B. Skirstad \& I. Waddington (Eds.) Pain and injury in sport - social and ethical analysis, (London and New York, Routledge), 182-199. 
WHO. (2010): Child maltreatment. Fact Sheet 150. Retrieved December 19, 2011, from http://www.who.int/mediacentre/factsheets/fs150/en/index.html

Young, K. (2004) Sporting Bodies, Damaged Selves (Oxford, Elsevier).

Young, K., McTeer, W. \& White, P. (1994) Body talk: male athletes reflect on sport, injury and pain, Sociology of Sport Journal, 11(2), 175-194.

Formatted: Font: Not Italic 